\title{
Columnar-to-Equiaxed Transition in Metal-Matrix Composites Reinforced with Silicon Carbide Particles
}

\author{
Alicia E. Ares ${ }^{1,2}$ and Carlos E. Schvezov ${ }^{1,2}$ \\ ${ }^{1}$ Faculty of Sciences, University of Misiones, 1552 Félix de Azara Street, 3300 Posadas, Misiones, Argentina \\ ${ }^{2}$ Member of Scientific Research Career (CIC) of the National Council of Scientific and Technical Research (CONICET), \\ 1917 Rivadavia Street, 1033 Buenos Aires, Argentina
}

Correspondence should be addressed to Alicia E. Ares; aares@fceqyn.unam.edu.ar

Received 30 July 2013; Accepted 4 November 2013

Academic Editor: Menahem Bamberger

Copyright (C) 2013 A. E. Ares and C. E. Schvezov. This is an open access article distributed under the Creative Commons Attribution License, which permits unrestricted use, distribution, and reproduction in any medium, provided the original work is properly cited.

\begin{abstract}
The present work is focused on the study of the effect of directional heat extraction on the silicon-carbide (SiC) distribution in zinc-aluminum matrix composites (MMCs) and on the columnar-to-equiaxed (CET) position in directionally solidified samples. To this end, a ZA-27 alloy matrix was reinforced with ceramic particles of SiC and vertically directionally solidified. The cooling rates, temperature gradients, and interphase velocities were then measured, and their influence on the solidification microstructure of the MMCs was analyzed. The recalescence detected and measured during the equiaxed transition was of the order of $3.5^{\circ} \mathrm{C}$ to $1.1^{\circ} \mathrm{C}$. The values of the temperature gradients reached a minimum during the CET and were even negative in most cases (between $-3.89 \mathrm{~K}$ and $0.06 \mathrm{~K}$ ). The interphase velocities varied between $0.07 \mathrm{~mm} / \mathrm{s}$ and $0.44 \mathrm{~mm} / \mathrm{s}$ at the transition. Also, the presence of ceramic particles in ZA-27 alloys affected the thermodynamic local conditions and the kinetics of nucleation, producing a finer microstructure.
\end{abstract}

\section{Introduction}

A metal-matrix composite (MMC) is composite material with at least two constituent parts, with one being a metal. The other material may be a different metal or another material, such as a ceramic or organic compound. The matrix is the monolithic material into which the reinforcement is embedded and is completely continuous. The reinforcement does not always serve a purely structural task but is also used to change physical properties such as wear resistance, friction coefficient, or thermal conductivity. The reinforcement can be either continuous or discontinuous [1]. The aspect ratio of the reinforcement is an important quantity, because the degree of load transfer from the matrix to the reinforcement is directly proportional to the reinforcement aspect ratio. Particle or short fiber reinforced metals have a much lower aspect ratio, so they exhibit lower strengths than their continuous fiber counterparts, although the properties of these composites are much more isotropic $[1,2]$.

Metal-matrix composites can be processed by several techniques. Some of these important techniques are liquidstate processes (casting or liquid infiltration, squeeze cast- ing, or pressure infiltration), solid-state processes (diffusion bonding, deformation processing, powder processing, sinterforging, and deposition techniques), in situ processes, and spray-forming of particulate MMCs [2].

Metal-matrix particulate composites such as $\mathrm{SiC}$ particlereinforced aluminum can offer a $50-100 \%$ increase in Young's modulus over that of unreinforced aluminum, that is, the modulus being equivalent to that of titanium, but density that is about 33\% lower. In general, ceramic reinforcements (fibers, whiskers, or particles) have a coefficient of thermal expansion lower than that of most metallic matrices. On the other hand, when the composite is subjected to a temperature change, thermal stresses are generated in both components [3].

The development of composites obtained by solidification of alloys has made remarkable progress and their applications in automotive and aerospace industries have increased in recent decades. Among these applications, the most current one is the zinc and aluminum base.

It is important for metallurgical processes to establish relationships between thermal parameters and solidification structures, because the solidification structure encompasses 
TABLE 1: Liquidus temperature $\left(T_{L}\right)$, solidus temperature $\left(T_{S}\right)$, cooling rate in the liquid $\left(\dot{T}_{L}\right)$, cooling rate in the solid $\left(\dot{T}_{S}\right)$, liquidus interphase velocity $\left(V_{\mathrm{LC}}\right)$, minimum CET position ( $\left.\mathrm{CET}_{\mathrm{MIN}}\right)$, maximum CET position $\left(\mathrm{CET}_{\mathrm{MAX}}\right)$, critical gradients $\left(G_{\mathrm{C}}\right)$, and recalescence values $(R)$ obtained from the temperature versus time curves.

\begin{tabular}{|c|c|c|c|c|c|c|c|c|c|c|}
\hline $\begin{array}{l}\text { Experiment } \\
\text { number }\end{array}$ & Alloy and composite & $\begin{array}{l}T_{L} \\
(\mathrm{~K}) \\
\end{array}$ & $\begin{array}{l}T_{S} \\
(\mathrm{~K})\end{array}$ & $\begin{array}{c}\dot{T}_{L} \\
(\mathrm{~K} / \mathrm{s})\end{array}$ & $\begin{array}{c}\dot{T}_{S} \\
(\mathrm{~K} / \mathrm{s}) \\
\end{array}$ & $\begin{array}{c}V_{\mathrm{LC}} \\
(\mathrm{K} / \mathrm{s}) \\
\end{array}$ & $\begin{array}{c}\mathrm{CET}_{\mathrm{MIN}} \\
(\mathrm{mm})\end{array}$ & $\begin{array}{l}\mathrm{CET}_{\text {MAX. }} \\
(\mathrm{mm})\end{array}$ & $\begin{array}{c}G_{c} \\
(\mathrm{~K} / \mathrm{mm})\end{array}$ & $\begin{array}{r}R \\
\left({ }^{\circ} \mathrm{C}\right. \\
\end{array}$ \\
\hline 1 & Zn-27 wt.\% Al (ZA27) & 778.2 & 709.7 & 3.3 & 1.1 & 1.05 & 35 & 87 & -0.09 & 2.4 \\
\hline 2 & Zn-27 wt.\% Al (ZA27) & 778.2 & 709.7 & 2.2 & 0.8 & 1.4 & 21 & 44 & 0.06 & 1.1 \\
\hline 3 & $\mathrm{ZA} 27$ + 5vol\% SiC & 767.8 & 710.2 & 2.8 & 0.9 & 1.2 & 26 & 48 & -3.89 & 2.3 \\
\hline 4 & $\mathrm{ZA} 27+5 \mathrm{vol} \% \mathrm{SiC}$ & 767.8 & 710.2 & 3.4 & 1.0 & 2.4 & 41 & 63 & -1.52 & 2.5 \\
\hline 5 & $\mathrm{ZA} 27+8 \mathrm{vol} \% \mathrm{SiC}$ & 762.3 & 706.7 & 3.1 & 1.0 & 1.6 & 31 & 46 & -1.55 & 2.9 \\
\hline 6 & $\mathrm{ZA} 27+8 \mathrm{vol} \% \mathrm{SiC}$ & 762.3 & 706.7 & 2.3 & 0.8 & 1.35 & 21 & 43 & -1.1 & 3.5 \\
\hline 7 & $\mathrm{ZA} 27+16 \mathrm{vol} \% \mathrm{SiC}$ & 759.1 & 703.5 & 3.4 & 1.0 & 1.85 & 39 & 54 & -2.49 & 1.3 \\
\hline 8 & $\mathrm{ZA} 27+16 \mathrm{vol} \% \mathrm{SiC}$ & 759.1 & 703.5 & 2.1 & 0.8 & 0.9 & 17 & 43 & -1.01 & 3.0 \\
\hline
\end{tabular}

morphological aspects of different types of grains (columnar, equiaxed, or columnar-to-equiaxed transition) and dendrite structure (primary, secondary, or tertiary) along the distribution and state of aggregation of the second reinforcing phase.

The interaction between the parameters involved in the columnar-to-equiaxed transition (CET) phenomenon, which has gained considerable attention over the last decades, allows understanding the structure of ingot castings and optimizing the industrial practice [4-18].

The characteristics of metal-matrix composite materials are determined by their microstructure and internal interfaces, which are affected by their production and thermal mechanical prehistory. The microstructure covers the structure of the matrix and the reinforced phase. The chemical composition, grain and/or subgrain size, texture, precipitation behavior, and lattice defects are of importance to the matrix. The second phase is characterized by its volume percentage, its kind, its size, its distribution, and its orientation. Local varying internal tension due to the different thermal expansion behavior of the two phases is an additional influencing factor $[1,2,19]$.

From the past research it is known that rules developed for solidification of unreinforced metals cannot be applied directly to metal matrix composites. An important tool in the study of alloy solidification is the Bridgman furnace, which produces well-controlled steady-state directional solidification conditions.

Directional solidification can be used to investigate solidification modes, analyzing the thermal parameter (thermal gradient and growth velocity) variation during the solidification process. Nevertheless, alloy solidification in engineering castings is generally dendritic and thermal parameters are neither measured nor constant over the course of solidification [17-21].

The present work is focused on the study of the effect of directional heat extraction on the silicon-carbide ( $\mathrm{SiC}$ ) distribution in an aluminum matrix composite and on the CET position in directionally solidified samples. To this end, Zn27 wt.\% Al (ZA-27) alloy matrix was reinforced with ceramic particulates of $\mathrm{SiC}$ and was vertically directionally solidified. The thermal parameters (cooling rates, temperature gradients, and interphase velocities) were then measured, and their

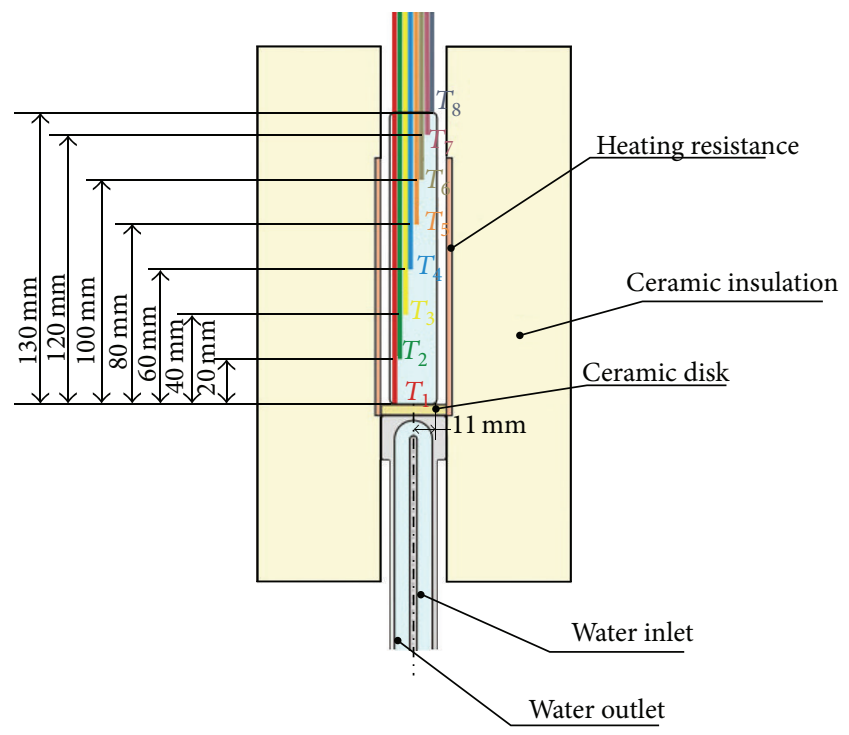

FIGURE 1: Details of the vertical experimental device.

influence on the solidification microstructure of the MMCs was analyzed. Experimental results include grain size and particle distribution as a function of the solidification conditions imposed by the metal/mould system. The conditions for the CET in MMCs are compared with those in $\mathrm{Zn}-\mathrm{Al}$ alloys.

\section{Experimental Procedure}

For the preparation of metal-matrix composites (MMCs), zinc (99.98 wt pct) and commercial aluminum (99.96 wt pct) were mixed with $\mathrm{SiC}$ particles. Their compositions are shown in Table 1.

The samples were melted and solidified directionally upwards in an experimental setup (see Figure 1) described elsewhere $[16,17]$. The procedure was as follows: at first, the liquid metal inside the mold in the furnace was allowed to reach the selected temperature. Once a uniform temperature was reached, less than 1 degree of difference recorded between the five thermocouples located at different positions 
in the melt, the furnace power was turned off and the melt was allowed to solidify from the bottom. Heat was extracted using a cooling system which consisted of a copper disk attached to a copper coil.

The temperature measurements were performed using Ktype (chromel/alumel) thermocouples $(1.8 \mathrm{~mm})$ which were protected with ceramic shields (i.d. $2.5 \mathrm{~mm}$, E.D. $3 \mathrm{~mm}$ ).

The thermocouples were previously calibrated using four temperature points: demineralized water at the freezing and boiling points (corrected by atmospheric pressure) and zinc (99.98 wt pct) and aluminum (99.96 wt pct) at their melting points. The accuracy of the thermocouples was determined to be about $\pm 0.5 \mathrm{~K}$. The samples were melted in ceramic molds (i.d. $2.3 \mathrm{~mm}$, E.D. $2.7 \mathrm{~mm}$ ).

The liquidus and solidus temperatures for each alloy were determined using two methods.

(1) The differential thermal analysis (DTA) system, NETZSCH STA 449 C with calibrated cells with pure elements was used. The DTA measurements were carried out with a charge of $200 \mathrm{mg}$ of premelted samples in alumina crucibles in an Argon atmosphere. The heating and cooling velocities were $10^{\circ} \mathrm{C} / \mathrm{min}$. The liquidus $\left(T_{L}\right)$ and solidus $\left(T_{S}\right)$ temperatures were taken from the heating and cooling curves as usual $[22,23]$.

(2) Determining the start and the end of solidification at each thermocouple by the changes in the slopes of the cooling curve at the start and the end of solidification. This criterion was chosen to allow undercooling to occur before solidification and possible recalescence during solidification of equiaxed grains.

The results between two methods (Table 1) are within 5\% error and within the predicted values given by the phase diagram [24].

After solidification, the samples were cut in an axial direction, polished with emery paper up to 1000 grit and $1 \mu \mathrm{m}$ alumina using a low speed machine, and etched with a mix containing chromic acid $\left(50 \mathrm{~g} \mathrm{Cr}_{2} \mathrm{O}_{3}, 4 \mathrm{~g} \mathrm{Na}_{2} \mathrm{SO}_{4}\right.$ in $100 \mathrm{~mL}$ of water) for approximately 10 seconds at room temperature [25]. The position of the transition was located by visual observation and optical microscopy and the distance from the chill zone of the sample was measured with a ruler.

The average grain size and volume fraction were determined according to the ASTM E 112-88 and ASTM E 56289 techniques, respectively $[26,27]$. The size, volume, and number of particles in three dimensions were determined using Saltykov's modification of Johnson's method [28]. The number of particles was determined by means of a grid method, dividing one section in 64 squares of $20 \times 20 \mathrm{~mm}$ uniformly distributed. The number of repetitions in each case ensured a representative distribution in each sample. The particle volume distribution was obtained using the standard norm ASTM E562-89. The density of average sizes of particles was determined by quantifying the repetitions of size of different particles in the grid. An average of the distribution

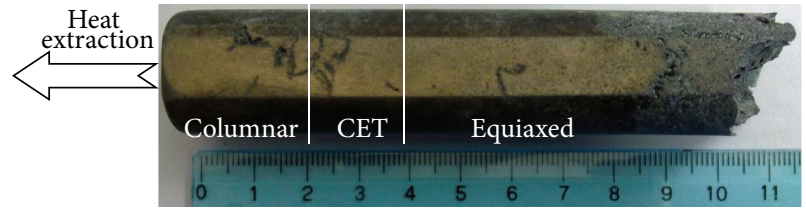

(a)

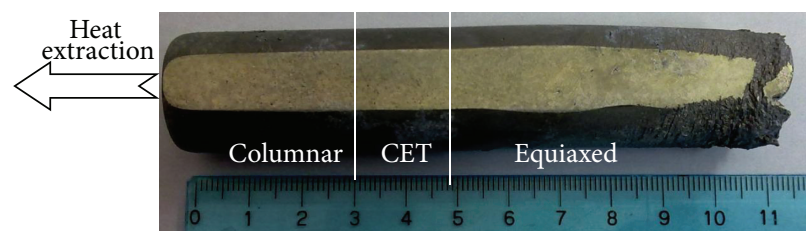

(b)

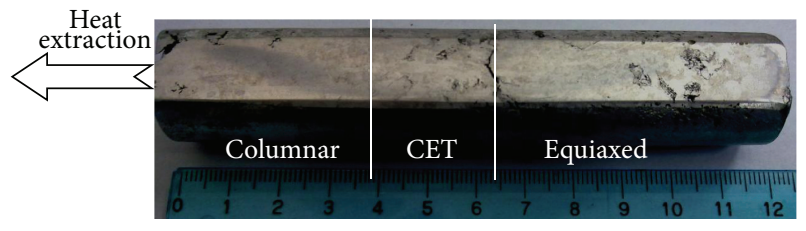

(c)

FIGURE 2: CET for three different composites: (a) ZA27+5 vol\% SiC, (b) ZA27+8 vol\% $\mathrm{SiC}$, and (c) ZA27+16 vol\% SiC.

of sizes was obtained. Particle size ranged between $1.56 \mu \mathrm{m}$ and $20.79 \mu \mathrm{m}$ of average diameter.

The microstructure was analyzed with optical and scanning electron microscopy (SEM). The distribution of elements in the microstructure was determined using EDXA. A Rigaku X-ray diffraction (XRD) system (Rigaku MSC, the Woodlands, TX, USA) was used for the XRD analysis of the alloys and composites.

\section{Results and Discussion}

3.1. Macrostructures and Microstructures. Eight experiments were performed with different alloy and composite compositions and cooling rates. The typical macrostructures of the transition for (a) ZA27+5 vol\% SiC, (b) ZA27+8 vol\% SiC, and (c) ZA27+16 vol\% SiC are shown in Figure 2.

As reported elsewhere for other alloys [10, 11, 16, 17], the transition is not sharp, showing a zone where some equiaxed grains coexist with columnar grains. The size of the transition zone is in the order of up to ten millimeters between the minimum position of the CET ( $\mathrm{CET}_{\text {MIN. }}$ ) and the maximum position of the CET ( $\mathrm{CET}_{\text {MAX. }}$ ). Also, no effect of the set of the thermocouples in the transition is observed; that is, the set of the thermocouples in the transition neither acted as nucleating sites nor changed the solidification structure.

The solidification microstructure of $\mathrm{Zn}-27 \mathrm{wt} . \% \mathrm{Al}$ (ZA27) alloy without the presence of particles (Figure 3) presented a dendritic structure consisting of primary dendrites rich in aluminum. The $\alpha+\eta$ eutectoid is formed during the final stage of solidification, from $\alpha$ dendrites and $\beta$ peritectic through a transformation at $548 \mathrm{~K}$, following the $\mathrm{Zn}$-Al phase diagram. This $\alpha+\eta$ eutectoid has a typical platelike form of $\alpha$ and $\eta$ sheets and a standard and finer eutectic 


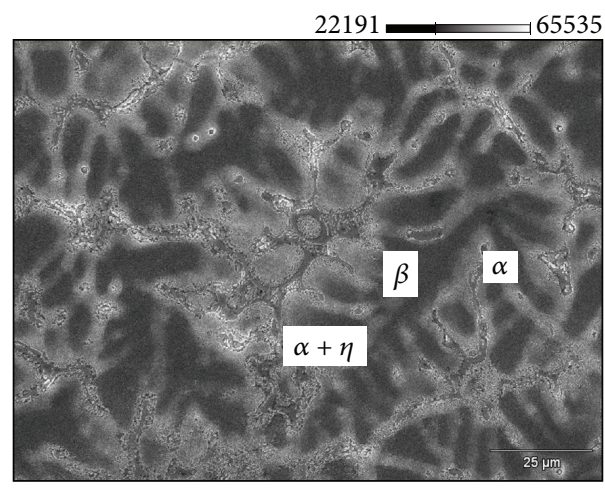

(a)

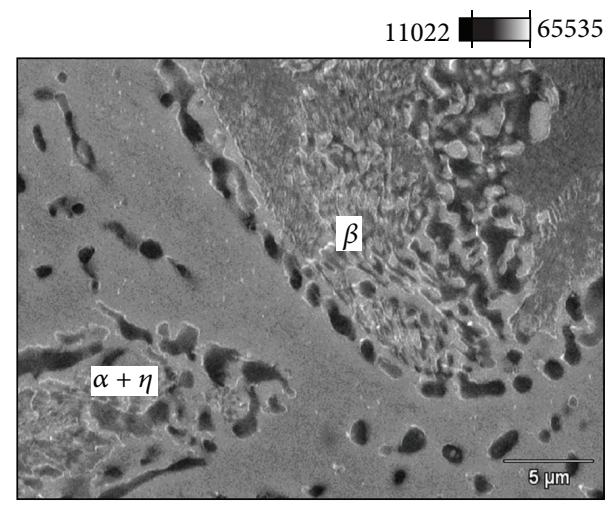

(b)

Figure 3: Microstructure of a Zn-27 wt.\% Al (ZA27) alloy. The $\alpha+\eta$ eutectoid is formed during the final stage of solidification, from $\alpha$ dendrites and $\beta$ peritectic through a transformation at $548 \mathrm{~K}$, following the $\mathrm{Zn}-\mathrm{Al}$ phase diagram.

structure. With the addition of silicon to the alloy, the phases and microstructures were the same as those in ZA27 alloys. However, silicon in the microstructure appears in two forms: in solution and as a precipitate [16]. As an example, in Figures 4(a), 4(b), and 4(c) the distributions of $\mathrm{Si}, \mathrm{Al}$ and $\mathrm{Zn}$ in the matrix of Figure 4(c) are shown.

Figure $4(\mathrm{c})$ shows the matrix with silicon precipitates and with $\mathrm{SiC}$ particles, respectively. The precipitates appear mostly in the dendritic cores, which indicates that the precipitates form in the melt and the grains possibly nucleate on them. Moreover, the particles appear mostly in the interdendritic regions as opposed to the silicon precipitates, as shown in Figure 4(d).

The SiC particles are clearly distinguished from the silicon precipitates because the precipitates have a light gray color, whereas the particles have a dark gray color, and because the precipitates have irregular contours, whereas the particles have sharp corners.

The samples present some degree of porosity, which increases from the bottom to the top of the casting, following the increase in the number of $\mathrm{SiC}$ particles (Figure $4(\mathrm{e})$ ). Gas porosity can sometimes be difficult to distinguish from microshrinkage because microshrinkage cavities can contain gases as well (shrinkage defects occur when feed metal is not available to compensate for shrinkage as the metal solidifies).
In general, microporosities will form if the casting is not properly risered or if a material with a wide solidification range is cast. If neither of these are the case then most likely the porosity is due to gas formation. In aluminum castings, hydrogen is the only gas that dissolves in significant quantity, which can result in hydrogen gas porosity. For castings that are a few kilograms in weight the pores are usually 0.01 to $0.5 \mathrm{~mm}$ in size [29].

The distribution of particles along the samples is not uniform (Figure 5). In this case, three distributions, corresponding to the columnar, CET, and equiaxed zones, are shown. A higher density of smaller particles in the columnar zone, a more monotonic decreasing distribution with a larger number with larger particles in the equiaxed zone, and finally, a more uniform distribution of particles in the equiaxed zone with a more constant number of particles for each size were observed, independently of the nature of the particle and volume fraction. This shows that, as expected, the larger particles have floated in a degree which is not significant as estimated. This could be attributed to the same solidification process itself. The chance of flotation is expected to be limited to the period of columnar solidification when the melt is completely fluid. As soon as the transition starts, there are two effects which decrease the degree of flotation: one associated with the equiaxed grains which start to solidify almost homogeneously considering the fast advance of the liquidus front as shown before; and an increase in melt viscosity (as well as in effective viscosity) due to the low temperature of the melt. Both conditions lead to a lower mobility of the particle and to a decrease in melt viscosity due to the temperature and increase in tortuosity and to the increase in the effect of viscosity due to the presence of the equiaxed grains.

The effect of the presence of foreign ceramic particles in the ZA alloys can be seen by analyzing the grain size distribution along the samples shown in Figures 6(a) and 6(b), which correspond to the grain size as a function of the position in the sample, along the direction of solidification, including the three zones (columnar, CET, and equiaxed). In the case of the columnar grains, the dimension shown is the columnar width perpendicular to the solidification direction.

The size distributions shown correspond to the $\mathrm{Zn}$ 27 wt.\% $\mathrm{Al}$ alloy and the same alloy with $\mathrm{SiC}$ particles $16 \%$ in volume of particles. The first observation made is that the addition of particles in all cases caused a reduction in grain size in the three zones. The degree of reduction depends on the zone, the particle density, and the nature of the particle. In addition, the transition changed from columnar to equiaxed. Focusing on the columnar zone, it is observed that the $\mathrm{SiC}$ particles lead to a two- to three-fold decrease in columnar width, which increases with volume particle. This effect is independent of the number of particles added.

During the transition, the size of the equiaxed grains is always smaller than the columnar width, as observed in other alloys $[16,17]$. Moreover, as in most cases, size increases after the transition until a maximum is reached and then normally decreases slightly again until the end of solidification.

However, the addition of particles produces a finer structure than in the columnar zone and the equiaxed grain size is never larger than the columnar width, as opposed to the case 


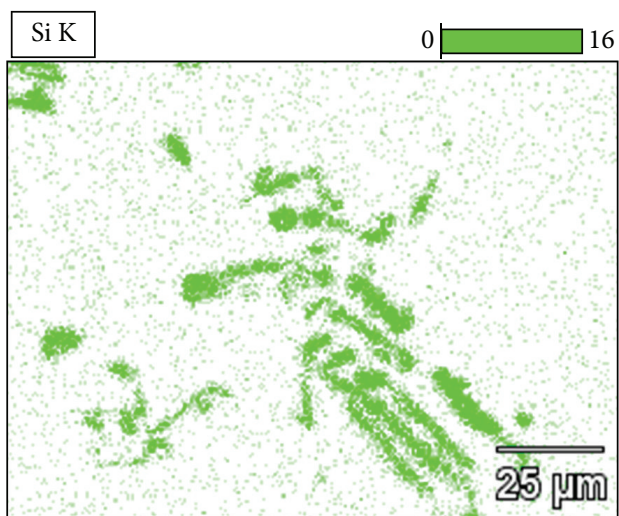

(a)

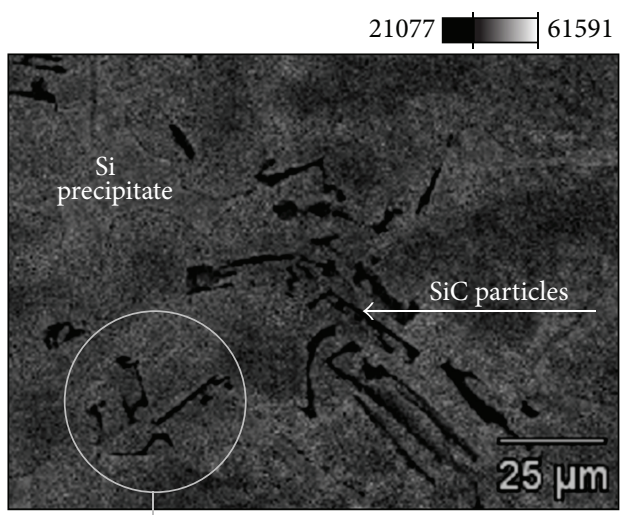

(c)

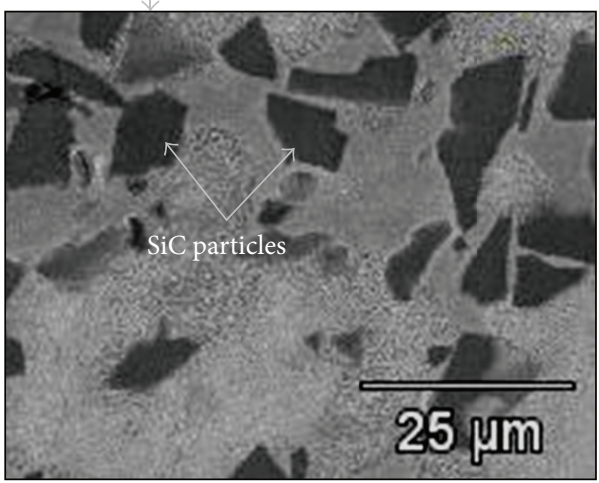

(d)

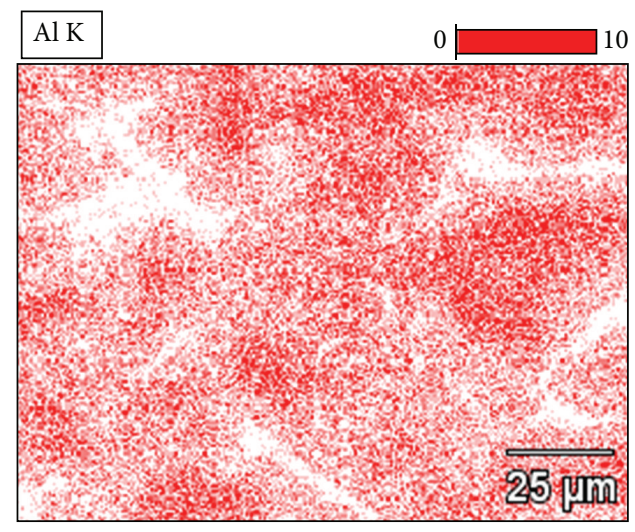

(b)
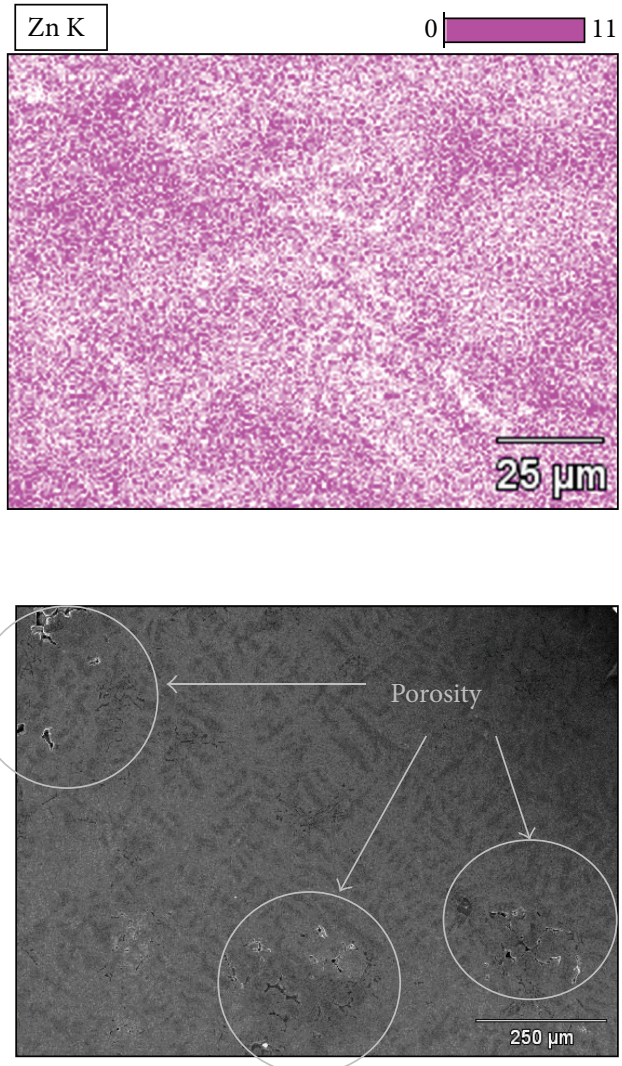

(e)

FIgURE 4: Microstructure of ZA27+5 vol\% SiC, showing the distribution of elements, precipitates, and SiC particles.

observed for the ZA27 alloy in Figure 6(a), where the grains are as large as $5 \mathrm{~mm}$ and the composites are rarely larger than $1 \mathrm{~mm}$, independently of the particle volume fraction.

This indicates a large effect of particle addition in the resulting microstructure. This result may be caused by a number of effects related to the particular solidification conditions during nucleation, solidification, and growth, which are both affected by the particles in the light of the results. The finer structure caused by particle addition is in concordance with the results obtained by Auras and Schvezov [4] and by Lo et al. [30] and opposite to those of Karni et al. [31].
It is interesting to note that the macroscopic heat extraction rate is similar for all 8 experiments; at the moment of the transition, the value of the heat extraction, $\mathrm{Q}_{\text {Crit. }}$, is between 1200 and $3100 \mathrm{~W} / \mathrm{m}^{2}$. This indicates that the effect producing a finer structure is mostly local. A finer structure may be produced by a nucleating agent and/or a larger supercooling.

The first situation is unlikely because the ceramic particles do not promote nucleation due to the surface tension which produces an unfavorable thermodynamic condition increasing the free energy. This is also supported by the observation that most of the particles appear in the interdendritic regions 


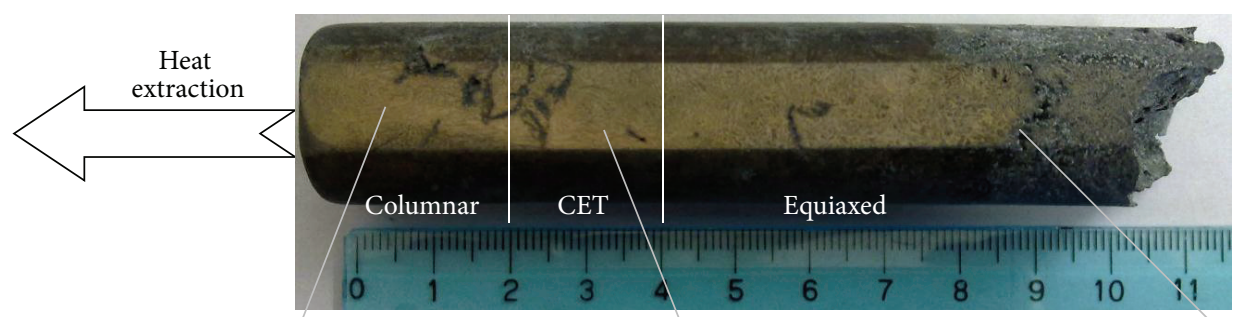

(a)

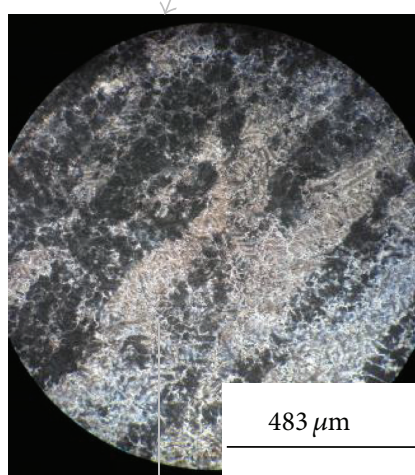

(b)

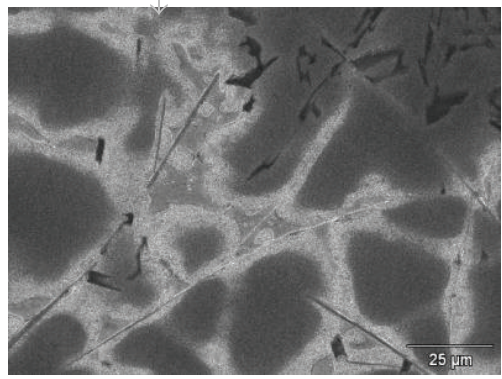

(e)

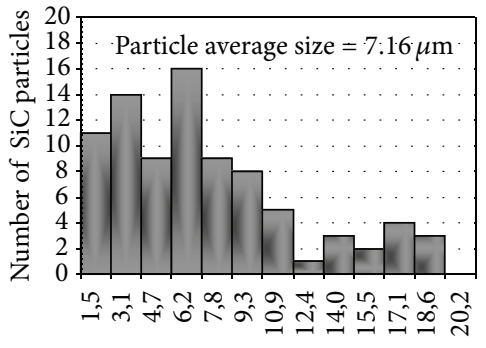

Size of SiC particles $(\mu \mathrm{m})$

口 Position 1 (columnar zone, 5 vol\% $\mathrm{SiC}$ )

(h)

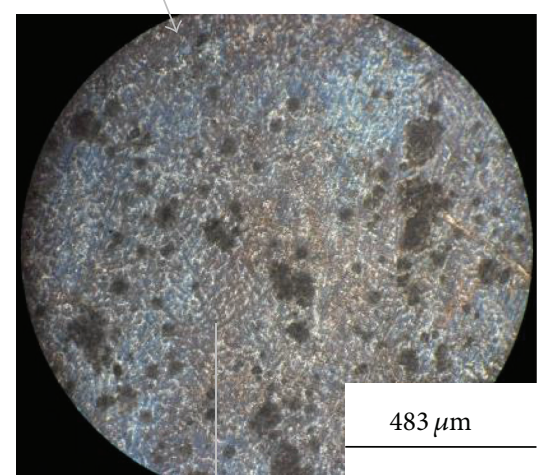

(c)

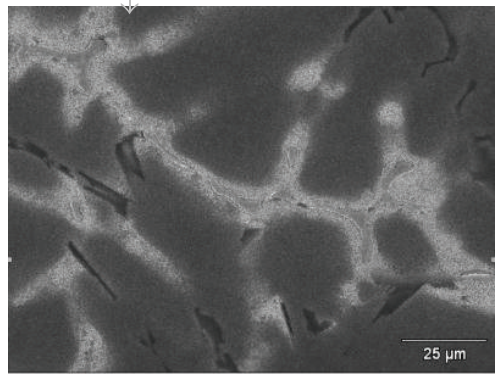

(f)

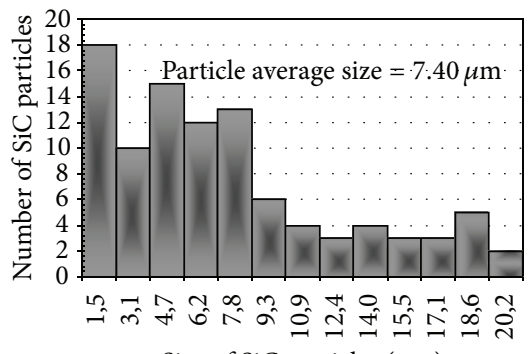

Size of SiC particles $(\mu \mathrm{m})$

․ Position 3 (CET zone, 5 vol\% $\mathrm{SiC}$ )

(i)

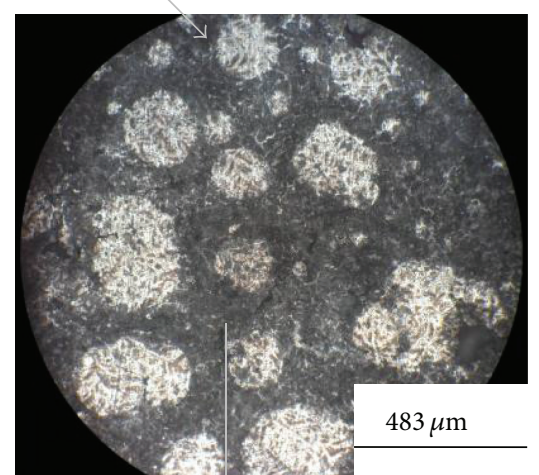

(d)

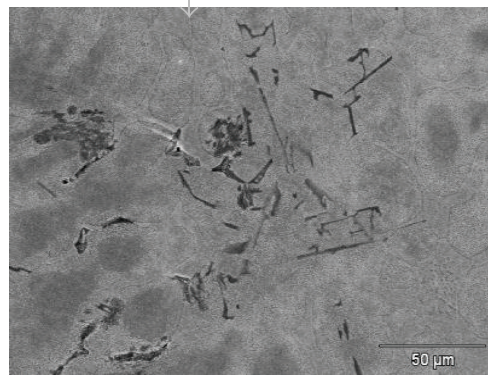

(g)

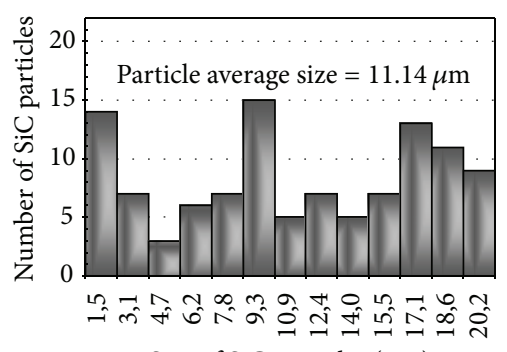

Size of SiC particles $(\mu \mathrm{m})$

ㅁ Position 5 (equiaxed zone, 5 vol\% $\mathrm{SiC}$ )

(j)

Figure 5: (a) CET for ZA27+5 vol\% SiC composite. Also, micrographs in each zone: ((b) and (e)) columnar, ((c) and (f)) CET, ((d) and (g)) equiaxed. (h)-(j) Particle distribution in columnar, CET, and equiaxed zones.

and not inside the dendrite trunks, which would be the situation if the particles act as nucleation sites for the equiaxed grains.

3.2. Temperature Measurements. The typical time-dependent temperatures measuredby the thermocouples in each posi- tion of the samples with a CET are shown in Figure 7 for ZA27 +16 vol\% SiC.

In the figure, the thermocouple $T_{1}$ is at the lowest position, and is the first to reach the solidification front, whereas $T_{8}$ is at the highest position. In all the curves, it is possible to identify a period corresponding to the cooling 


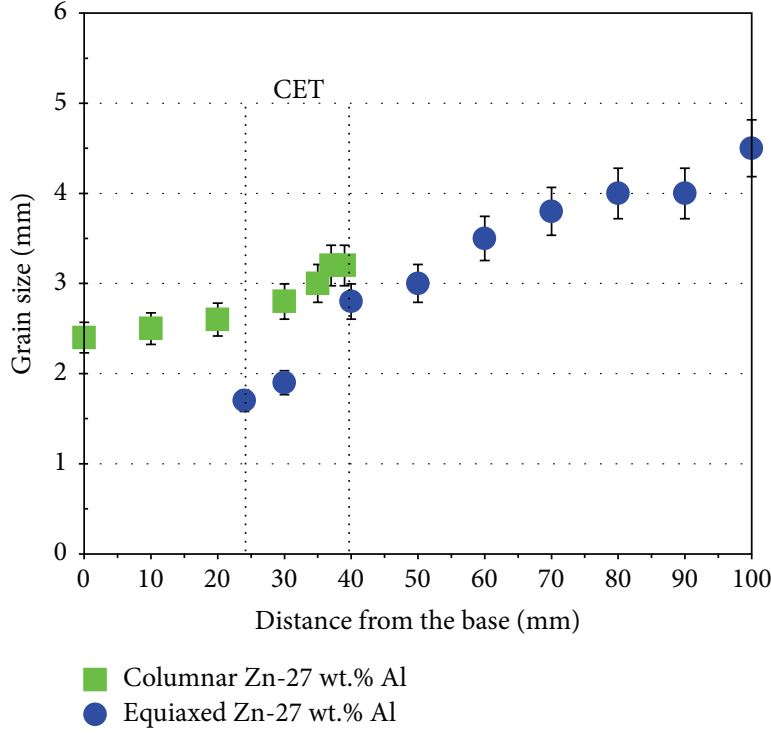

(a)

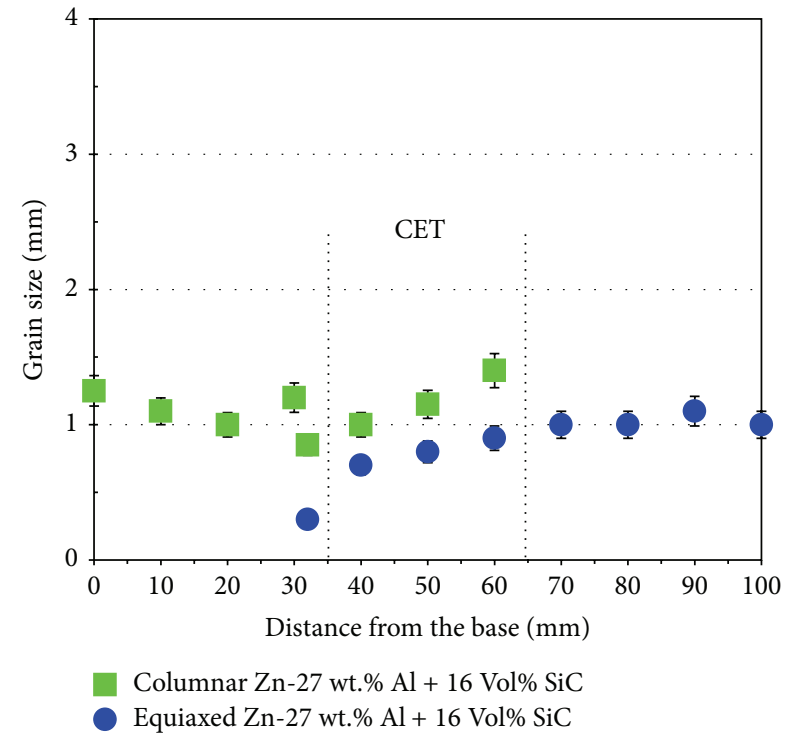

(b)

Figure 6: Grain size versus distance from the bottom of the sample. (a) Zn-27 wt.\% Al.; (b) ZA27+16 vol\% SiC.

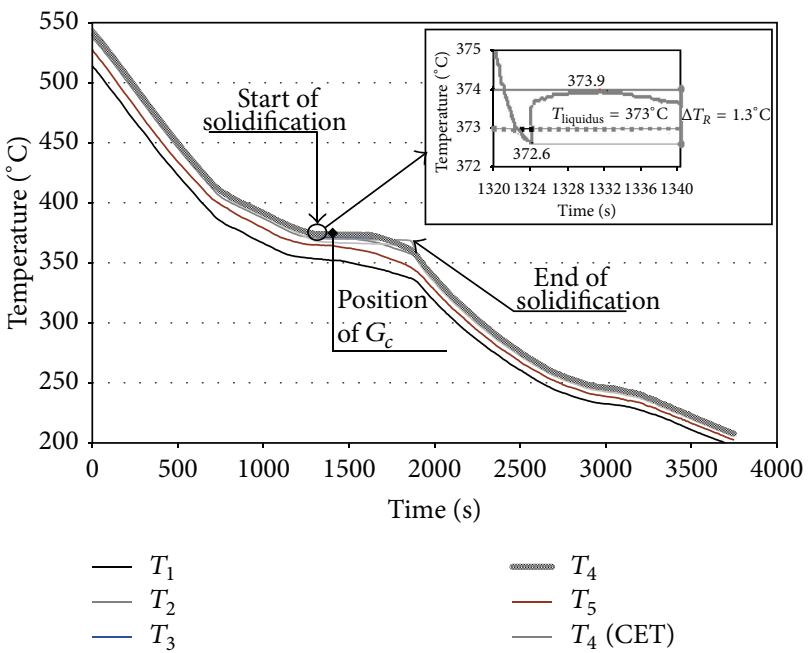

FIGURE 7: Cooling curve for ZA27 +16 vol\% SiC composite showing positions of critical temperature gradient for one thermocouple location (CET position), recalescence, and start and end of solidification.

of the melt, a second period of solidification, and a final period of cooling of the solid to ambient temperature.

3.3. Solidification Parameters. The data shown in Figure 7 allow extracting the following information: melt superheat, cooling rate of the melt and the solid, position of the solidification fronts for the solidus and the liquidus temperatures, local solidification time, velocity of both solidification fronts, length of the mushy zone, temperature gradients and recalescence.

In some cases, the quantification of these parameters is straightforward. This is the case of melt superheat, which is the difference between the highest temperature above the liquidus reached by the melt before the furnace is turned off and the liquidus temperature. It is also the case of the cooling rate, which is calculated as the slope of the temperature versus time curve in both periods, the cooling of the melt and the solid. The method used to calculate the parameters from the temperature versus time curves has been reported before [10-13, 16, 17].

The change in slope of the temperature versus time curve measured for the liquidus temperature, $T_{L}$, or the start of solidification was typically around $2.1 \mathrm{~K} / \mathrm{s}$, whereas that for the solidus temperature, $T_{S}$, or the end of solidification was around $0.9 \mathrm{~K} / \mathrm{s}$. Both $T_{L}$ and $T_{S}$ are given in Table 1 .

3.4. Cooling Rate. The cooling rate in the liquid alloy was determined from the temperature versus time curves at each thermocouple position, which was calculated as the slope of the temperature curve in both periods that refer to (a) the cooling rate of the melt (liquid), $\dot{T}_{L}$, and (b) the cooling rate of the solid, $\dot{T}_{S}$.

The temperature versus time plot for one experiment is presented in Figure 7 . The cooling rate in the melt, $\dot{T}_{L}$, and the cooling rate of the solid, $\dot{T}_{S}$, both calculated from this type of curves are listed in Table 1 for all the experiments; velocities of $2.0 \mathrm{~K} / \mathrm{s}$ to $3.5 \mathrm{~K} / \mathrm{s}$ were produced. Table 1 also lists the location of the transition from the bottom of the sample which is in the range of $\mathrm{CET}_{\text {MIN. }}$ to $\mathrm{CET}_{\mathrm{MAX}}(\mathrm{cm})$. Comparing the cooling velocities with the distances which correspond to the length of the columnar zone, it is observed that the length of the columnar grains $\left(\mathrm{CET}_{\mathrm{MAX}}\right)$ increases as the velocity increases.

The temperature versus time curves also show that the temperature evolution depends on the structure being formed. During columnar solidification, the temperature decreases steadily and monotonically, whereas in the equiaxed region, during the $\mathrm{CET}$, there is a recalescence 


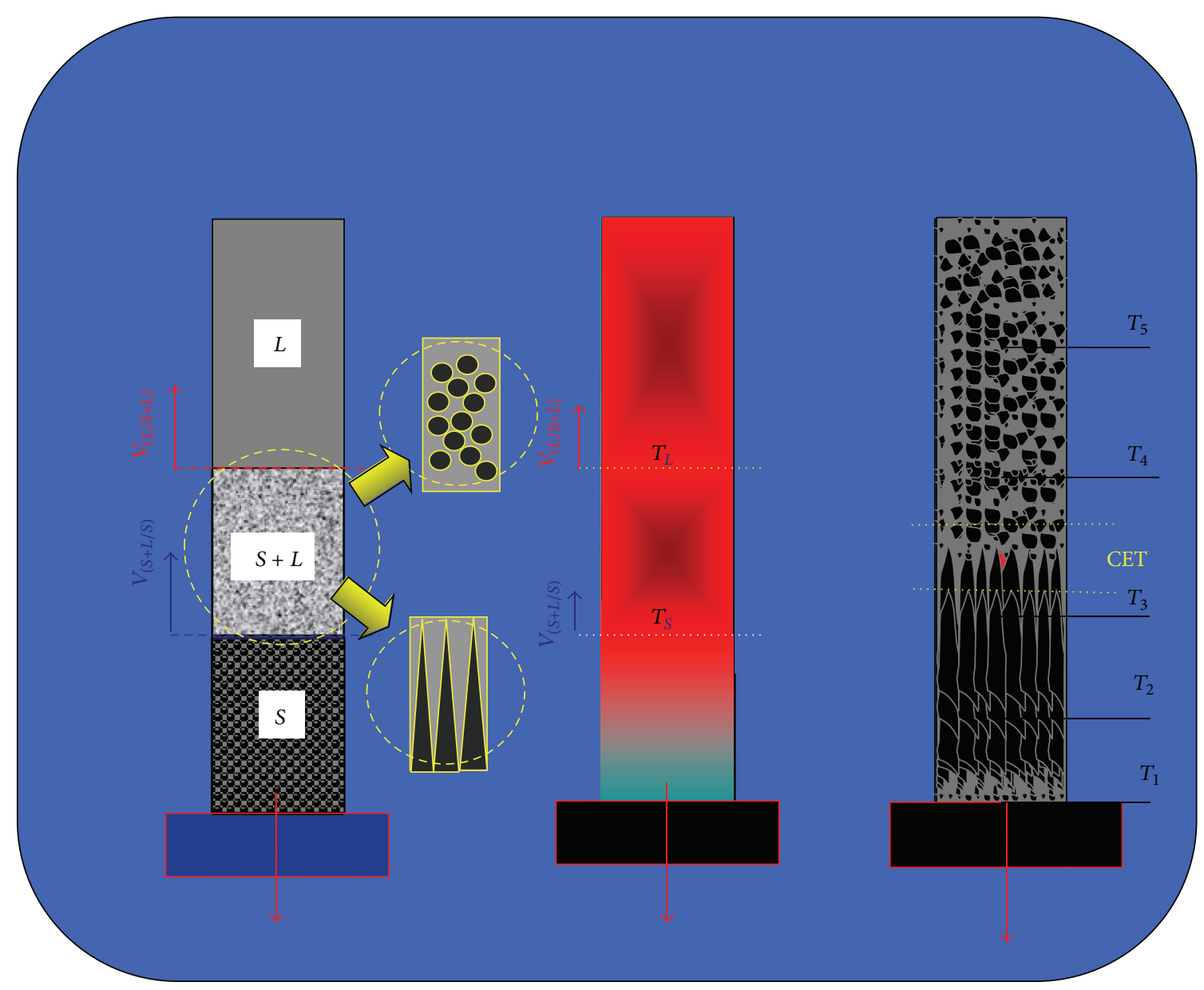

(a)

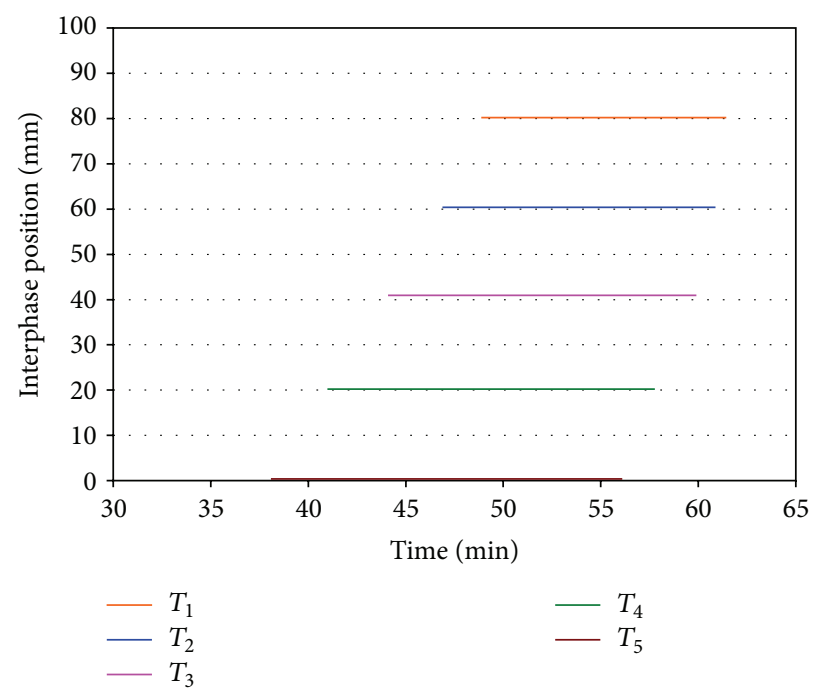

(b)

FIGURE 8: Interphase position versus time during solidification of composites. (a) Schematic and (b) ZA27+16 vol\% SiC. 


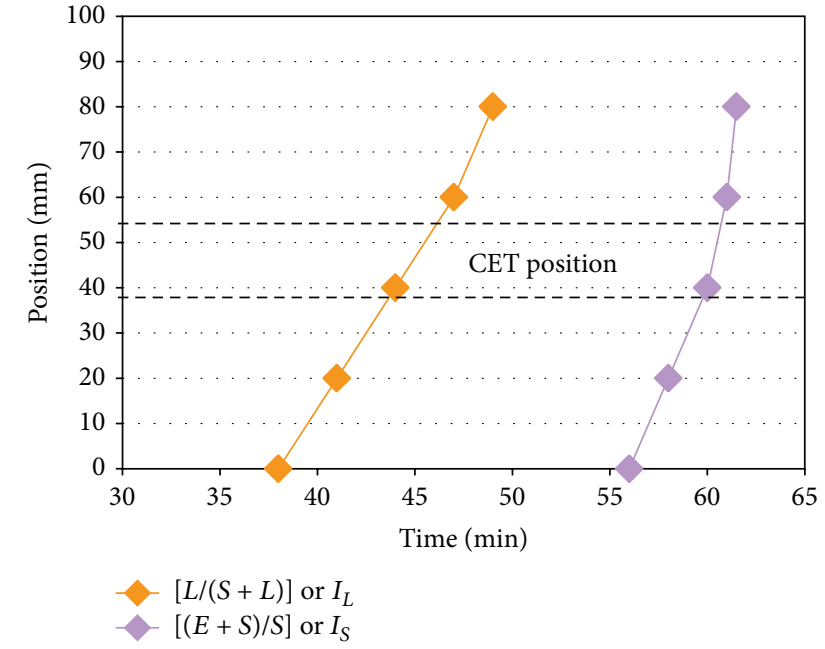

FIGURE 9: Liquid $(L)$ and solid $(S)$ interphase positions. $\mathrm{ZA} 27+16$ vol\% SiC.

which increases the temperature from a minimum; the level of recalescence for each experiment is listed in Table 1 as $R$ $\left({ }^{\circ} \mathrm{C}\right)$ and it is shown in the inset of Figure 7 for experiment number 7 .

3.5. Solidification Velocity. The solidification velocity was determined from the time recorded from the start to the end of solidification at each thermocouple position (the separation between thermocouples was $20 \mathrm{~mm}$ ). The position of the interphases for one experiment with composites is shown in Figures 8(a) and 8(b). A uniform motion of the liquidus and solidus interphases is observed as in the case of $\mathrm{Zn}-\mathrm{Al}$ alloys reported before [13]. The horizontal bar in each position indicates the time it takes the temperature to go from the liquidus to the solidus temperature, that is, the local solidification time versus liquidus and solidus interphases. The velocities can easily be calculated from these types of figures or from Figure 9 for the same experiments.

In both cases, an acceleration of the interphase movement, which becomes particularly relevant at the transition from columnar to equiaxed solidification, can be observed. It is also observed that the liquidus interphase accelerates faster than the solidus one. The numerical values of both velocities at the transition are listed in Table 2.

The position of the interphase as a function of the difference in time for each thermocouple is used to define a parameter which is called the local solidification velocity $\left(V_{\mathrm{SL}}\right)$ using the following equation [18]:

$$
V_{\mathrm{SL}}=\frac{V_{L} * V_{S}}{V_{L}-V_{S}} .
$$

It is possible that this local solidification velocity acquires subsequent values:
(a) $V_{L}=V_{S} \Rightarrow V_{\mathrm{SL}} \rightarrow \infty$,
(b) $V_{\mathrm{SL}}>0 \Rightarrow V_{L}>V_{S}$,

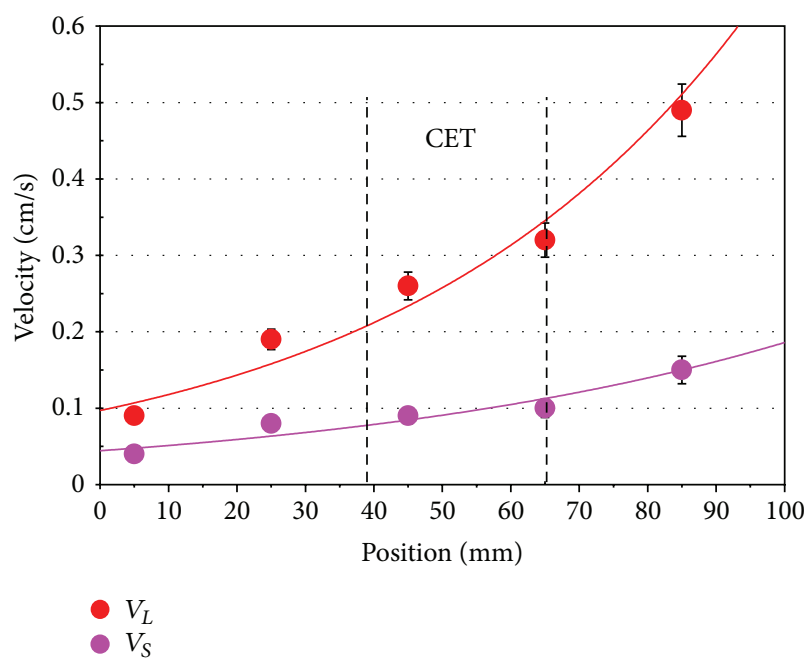

FIgURE 10: $V_{L}, V_{S}$ and $V_{\mathrm{SL}}$ versus time. ZA27+16 vol\% $\mathrm{SiC}$.

(c) $V_{\mathrm{SL}}<0 \Rightarrow V_{L}<V_{S}$,

(d) $V_{\mathrm{SL}}=0 \Rightarrow V_{L}=V_{S}=0$.

In Table 2, $V_{\mathrm{SL}}$ is negative between the first two thermocouples at the bottom, indicating that the solid interphase moves faster than liquid interphase, reducing the size of the mushy zone. After this, the liquid interphase accelerates faster than the solidus one, giving positive values for $V_{\mathrm{SL}}$ and increasing the size of the mushy zone.

Figure 10 shows the different velocities, $V_{L}, V_{S}$, and $V_{\mathrm{SL}}$, obtained for one of the experiments. In this case, both the velocities of the solid and liquid interphase accelerate during and after the transition, resulting in a $V_{\mathrm{SL}}$ which also increases drastically, leading to a larger mushy zone. The highlighted boxes in Table 2 correspond to the liquidus velocities obtained at the critical point of the CET $\left(V_{\mathrm{LC}}\right)$. The observation here is that these values are nearly the largest obtained in each experiment, indicating the acceleration of the liquidus interphase at the transition.

3.6. Temperature Gradients. The temperature gradients, $G$, were calculated for each pair of neighboring thermocouples as the temperature difference between the thermocouple readings divided by the separation distance between thermocouples.

The values of gradients are plotted in Figure 11 for one experiment and for each type of composite. In all the figures it is observed that from the beginning of solidification, the gradients decrease with the time. The minimum value always corresponds to the position of the CET. The gradients shown for the experiment in Figure 11(a) reach negative values at this point $\left(-2.49^{\circ} \mathrm{C} / \mathrm{cm}\right)$. This negative value indicates a reversal in the temperature profiles ahead of the interface, which could be associated with the recalescence due to massive nucleation of equiaxed grains, as previously reported and discussed for different alloys [10-13, 16, 17]. The critical temperature gradients for all experiments are presented in Table 1. 
TABLE 2: Liquid $\left(V_{L}\right)$ and solid $\left(V_{S}\right)$ interphase velocity and local solidification velocity $\left(V_{\text {SL }}\right)$.

\begin{tabular}{lcccccccccc}
\hline \multirow{2}{*}{ Experiment number } & \multirow{2}{*}{ Composite } & \multicolumn{3}{c}{$V_{L}(\mathrm{~mm} / \mathrm{s})$} & \multicolumn{3}{c}{$V_{S}(\mathrm{~mm} / \mathrm{s})$} & \multicolumn{3}{c}{$V_{\mathrm{SL}}(\mathrm{mm} / \mathrm{s})$} \\
& & $V_{L} 1$ & $V_{L} 2$ & $V_{L} 3$ & $V_{S} 1$ & $V_{S} 2$ & $V_{S} 3$ & $V_{\mathrm{SL}} 1$ & $V_{S L} 2$ & $V_{\mathrm{SL}} 3$ \\
\hline 3 & ZA27 + 5vol\% SiC & 0.02 & $\mathbf{0 . 1 5}$ & 0.21 & 0.02 & 0.03 & 0.06 & -1.00 & 0.14 \\
4 & ZA27 + 5vol\% SiC & 0.14 & 0.19 & $\mathbf{0 . 4 0}$ & 0.07 & 0.09 & -0.14 & 0.17 & 0.16 \\
5 & ZA27 + 8vol\% SiC & 0.09 & 0.09 & $\mathbf{0 . 4 4}$ & 0.12 & 0.04 & 0.14 & 0.14 & 0.09 & 0.10 \\
6 & ZA27 + 8vol\% SiC & 0.04 & 0.07 & $\mathbf{0 . 2 3}$ & 0.04 & 0.07 & 0.14 & -1.49 & -1.13 & -1.07 \\
7 & ZA27 + 16vol\% SiC & 0.03 & 0.24 & $\mathbf{0 . 2 7}$ & 0.02 & 0.10 & 0.14 & 0.07 & 0.17 & 0.30 \\
8 & ZA27 + 16vol\% SiC & 0.07 & $\mathbf{0 . 3 3}$ & 0.03 & 0.06 & 0.08 & 0.06 & 0.41 & 0.08 & -0.08 \\
\hline
\end{tabular}

TABLE 3: Predicted and measured CET positions for different composites.

\begin{tabular}{lcccc}
\hline Experiment number & Alloy and composite & CET $_{\text {predicted }}(\mathrm{mm})$ & CET $_{\text {measured }}(\mathrm{mm})$ & Relative error $(\%)$ \\
\hline 1 & Zn-27 wt.\% Al (ZA27) & 91 & 46 & 45 \\
2 & Zn-27 wt.\% Al (ZA27) & 47 & 47 & 4.49 \\
3 & ZA27 + 5vol\% SiC & 52 & 65 & 9.61 \\
4 & ZA27 + 5vol\% SiC & 69 & 47 & 5.79 \\
5 & ZA27 + 8vol\% SiC & 50 & 42 & 5.02 \\
6 & ZA27 + 8vol\% SiC & 46 & 53 & 7.01 \\
7 & ZA27 + 16vol\% SiC & 57 & 42 & 6.66 \\
8 & ZA27 + 16vol\% SiC & 45 & & \\
\hline
\end{tabular}

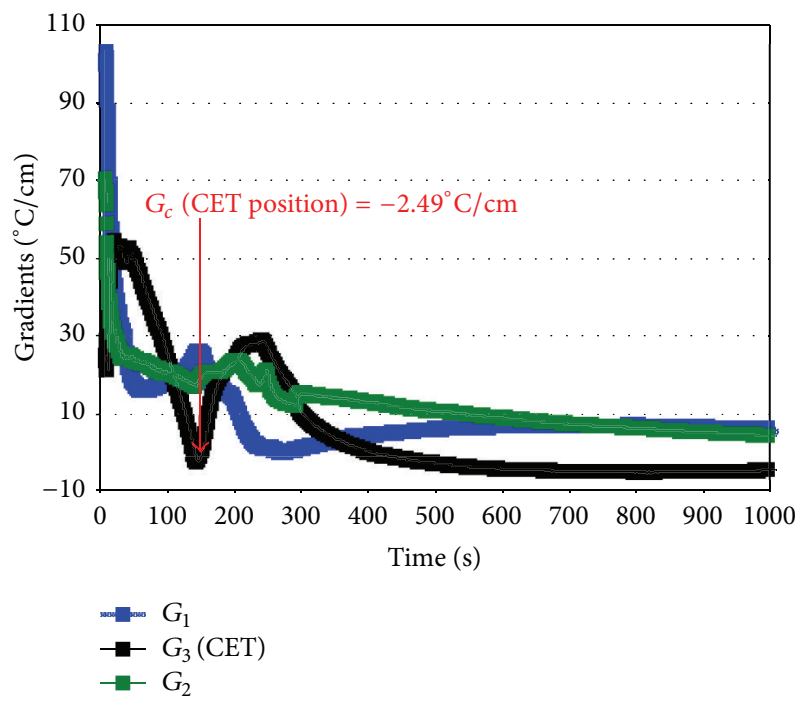

FIgURE 11: Temperature gradients versus time for ZA27+16 vol\% $\mathrm{SiC}$.

3.7. Semiempirical Modeling. The ceramic particles are more likely to act as retardants of the nucleation processes. This view is supported by the following facts associated with the dynamics during and after the transition. The two key parameters are the critical velocity of the liquidus front during the transition, $V_{\mathrm{LC}}$, and the temperature gradient in the region, $G_{C}$.

First, the $V_{\mathrm{LC}}$ is associated with the kinetics of nucleation of the equiaxed grains; $V_{\mathrm{LC}}$ in all cases accelerates very rapidly during and after the transition. $G_{C}$ indicates the degree of massivity and severity of the conditions present during the equiaxed nucleation, that is, the degree of supercooling necessary for nucleation and the recalescence product of the solidification process.

By comparing these two parameters for the ZA27 alloys with those for the composites, it is seen that the $V_{\mathrm{LC}}$ for the former is between 1.5 and $1.9 \mathrm{~mm} / \mathrm{s}$ and the average gradient measured is slightly negative but small. On the other hand, the reinforced alloys produce a $V_{\mathrm{LC}}$ that is similar and an average temperature gradient that is always negative. This indicates that the conditions required for nucleation in the presence of ceramic particles are more severe and that the kinetics of solidification once the transition starts is not affected because $V_{\mathrm{LC}}$ is similar in all cases.

Another parameter associated with the nucleation process is the recalescence; by comparing the recalescence for ZA27 and that for its composites, it is observed that there is no significant increase in the recalescence for the composites. The recalescence is associated with the mass of alloy that nucleates and not with the number of nuclei or the amount of heat that may be absorbed by the surrounding melt, which in turn is related to the amount of supercooling. Timetemperature measurements showed that recalescence occurs before the critical temperature gradient was reached (see Figure 7).

The overall solidification process is controlled and limited by the heat extraction from the solidification region given by $\mathrm{Q}_{\text {Crit }}$., which is similar for all cases.

On the other hand, the experimental observations and measurements show that the transition in the composites occurs when the temperature gradient reaches values below $0.1 \mathrm{~K} / \mathrm{mm}$ and the liquidus front velocity increases to values around 0.2 to $0.4 \mathrm{~mm} / \mathrm{s}$. Following these two conditions, the position of the transition may be located at any stage of solidification. Both the gradient and liquidus front velocities can be calculated using numerical techniques [8]. 
The calculation of the thermal field in Stefan's problem was done using an explicit finite difference method to solve the unidirectional heat flow equation. The latent heat of the solidifying material in the mushy zone was calculated using the enthalpy method [32, 33]. The specific heats and the thermal conductivities of solid and liquid were assumed as temperature and concentration dependent. The resulting nonlinear equations were linearized employing a modified temperature approach. The heat transfer coefficients at the bottom and top of the sample were determined as a function of temperature by inverse modeling.

The positions of the CET in MMCs predicted for the eight experiments are shown in Table 3. As it can be observed, the agreement between the model and the experimental results is reasonably good. The largest discrepancy is lower than $10 \%$.

\section{Conclusions}

The main results obtained in the present investigation may be summarized as follows.

(1) Metal-matrix composites were directionally solidified and the temperatures during the whole process were measured in the liquid and solid phases.

(2) For the three types of composites studied, the columnar-to-equiaxed transition (CET) was produced and the values of the temperature gradients calculated reached minimum values during the transition and were even negative in most cases.

(3) ZA27+16 vol\% SiC showed a second minimum of the gradient after the transition, indicating the importance and complexity of the solidification pattern of composites with technological interest.

(4) In the three types of composites studied an increase in the cooling velocity in the liquid was found to increase the columnar zone length.

(5) At the CET, the interphase velocities are high (between 0.07 and $0.44 \mathrm{~mm} / \mathrm{s}$ ) depending on the experiment.

(6) Recalescence was detected and measured during the equiaxed transition, being of the order of $3.5^{\circ} \mathrm{C}$ to $1.1^{\circ} \mathrm{C}$.

(7) The CET structure is not abrupt but occurs in a zone of $1 \mathrm{~cm}$ or larger. The same results were obtained for the binary zinc-aluminum alloys.

(8) The presence of ceramic particles in ZA27 alloys affects the thermodynamic local conditions and the kinetics of nucleation, producing a finer microstructure.

(9) The position of the CET in MMCs is predicted within a $10 \%$ error.

\section{Acknowledgments}

This work was partially supported by the Argentinean Research Council (CONICET) and the National Agency for Science and Technology (PICT-2011-1378).

\section{References}

[1] W. D. Callister Jr., Materials Science and Engineering: An Introduction, John Wiley \& Sons, New York, NY, USA, 7th edition, 2006.

[2] K. K. Chawla, Composite Materials: Science \& Engineering, Springer, New York, NY, USA, 2nd edition, 1999.

[3] K. K. Chawla and M. Metzger, Advances in Research on Strength and Fracture of Materials, vol. 3, Pergamon Press, New York, NY, USA, 1978.

[4] R. Auras and C. Schvezov, "Wear behavior, microstructure, and dimensional stability of as-cast zinc-aluminum/SIC (metal matrix composites) alloys," Metallurgical and Materials Transactions A, vol. 35, no. 5, pp. 1579-1590, 2004.

[5] J. D. Hunt, "Steady state columnar and equiaxed growth of dendrites and eutectic," Materials Science and Engineering, vol. 65, no. 1, pp. 75-83, 1984.

[6] R. B. Mahapatra and F. Weinberg, "The columnar to equiaxed transition in tin-lead alloys," Metallurgical Transactions B, vol. 18, no. 2, pp. 425-432, 1987.

[7] I. Ziv and F. Weinberg, "The columnar-to-equiaxed transition in $\mathrm{Al} 3 \mathrm{Pct} \mathrm{Cu}$," Metallurgical Transactions B, vol. 20, no. 5, pp. 731-734, 1989.

[8] C.-A. Gandin, "Experimental study of the transition from constrained to unconstrained growth during directional solidification," ISIJ International, vol. 40, no. 10, pp. 971-979, 2000.

[9] C.-A. Gandin, "From constrained to unconstrained growth during directional solidification," Acta Materialia, vol. 48, no. 10, pp. 2483-2501, 2000.

[10] A. E. Ares and C. E. Schvezov, "Solidification parameters during the columnar-to-equiaxed transition in lead-tin alloys," Metallurgical and Materials Transactions A, vol. 31, no. 6, pp. 1611-1625, 2000.

[11] A. E. Ares, S. F. Gueijman, and C. E. Schvezov, "Semi-empirical modeling for columnar and equiaxed growth of alloys," Journal of Crystal Growth, vol. 241, no. 1-2, pp. 235-240, 2002.

[12] A. E. Ares, S. F. Gueijman, R. Caram, and C. E. Schvezov, "Analysis of solidification parameters during solidification of lead and aluminum base alloys," Journal of Crystal Growth, vol. 275, no. 1-2, pp. e319-e327, 2005.

[13] G. Reinhart, N. Mangelinck-Noël, H. Nguyen-Thi et al., "Investigation of columnar-equiaxed transition and equiaxed growth of aluminium based alloys by X-ray radiography," Materials Science and Engineering A, vol. 413-414, pp. 384-388, 2005.

[14] H. Yasuda, I. Ohnaka, A. Sugiyama et al., "Time-resolved imaging of the microstructure evolution during dendritic solidification by using synchrotron radiation," in Modeling of Casting, Welding and Advanced Solidification Processes-XI, C.A. Gandin and M. Bellet, Eds., pp. 375-382, TMS, Warrendale, $\mathrm{Pa}$, USA, 2006.

[15] J. A. Spittle, "Columnar to equiaxed grain transition in as solidified alloys," International Materials Reviews, vol. 51, no. 4, pp. 247-269, 2006.

[16] A. E. Ares and C. E. Schvezov, "Influence of solidification thermal parameters on the columnar-to-equiaxed transition of aluminum-zinc and zinc-aluminum alloys," Metallurgical and Materials Transactions A, vol. 38, no. 7, pp. 1485-1499, 2007.

[17] S. F. Gueijman, C. E. Schvezov, and A. E. Ares, "Vertical and horizontal directional solidification of $\mathrm{Zn}-\mathrm{Al}$ and $\mathrm{Zn}$-Ag diluted alloys," Materials Transactions, vol. 51, no. 10, pp. 1861-1870, 2010. 
[18] A. E. Ares and C. E. Schvezov, "Metal matrix composites directionally solidified," in TMS 2013 Annual Meeting Supplemental Proceedings, pp. 1061-1068, TMS, John Wiley \& Sons, Warrendale, Pa, USA, 2013.

[19] K. U. Kainer, "Basics of metal matrix composites," in Metal Matrix Composites: Custom-Made Materials for Automotive and Aerospace Engineering, K. U. Kainer, Ed., Wiley-VCH GmbH \& Co. KGaA, Weinheim, Germany, 2006.

[20] A. Mortensen and M. C. Flemings, "Solidification of binary hypoeutectic alloy matrix composite castings," Metallurgical and Materials Transactions A, vol. 27, no. 3, pp. 595-609, 1996.

[21] N. F. Dean, A. Mortensen, and M. C. Flemings, "Liquid-state processing," in Fundamentals of Metal-Matrix Composites, P. K. Rohatgi, Ed., pp. 3-22, TMS, Warrendale, Pa, USA, 1993.

[22] R. F. Speyer, Thermal Analysis of Materials, Marcel Dekker, New York, NY, USA, 1994.

[23] Y. T. Zhu, J. H. Devletian, and A. Manthiram, "Application of differential thermal analysis to solid-solid transitions in phase diagram determination," Journal of Phase Equilibria, vol. 15, no. 1, pp. 37-41, 1994.

[24] W. J. Moffatt, The Handbook of Binary Phase Diagrams, General Electric Company Corporate Research and Development Technology Marketing Operation, New York, NY, USA, 1984.

[25] G. F. Vander Voort, Metallography Principles and Practice, ASM International, New York, NY, USA, 2000.

[26] E112-96el: ASTM Standards, vol. 03.01, ASTM, Philadelphia, Pa, USA, 1988.

[27] E562-02: ASTM Standards, vol. 03.01, ASTM, Philadelphia, Pa, USA, 1989.

[28] E. E. Underwood, "Particle size distribution," in Quantitative Microscopy, R. T. de Hoff and F. N. Rhines, Eds., pp. 76-101, 149199, McGraw-Hill, New York, NY, USA, 1968.

[29] B. Prillhofer, H. Böttcher, and H. Antrekowitsch, "Development and practical performance characteristics of a new impeller for metal treatment in casting/holding furnaces," in Light Metals 2009, p. 234, The Minerals, Metals \& Materials Society, 2009.

[30] S. H. J. Lo, S. Dionne, M. Sahoo, and H. M. Hawthorne, "Mechanical and tribological properties of zinc-aluminium metal-matrix composites," Journal of Materials Science, vol. 27, no. 21, pp. 5681-5691, 1992.

[31] N. Karni, G. B. Barkay, and M. Bamberger, "Structure and properties of metal-matrix composite," Journal of Materials Science Letters, vol. 13, no. 7, pp. 541-544, 1994.

[32] S. F. Gueijman, A. E. Ares, and C. E. Schvezov, "Enthalpy variations and latent heat evolution during solidification of lead tin alloys," in Light Metals 2000, pp. 615-621, TMS, Warrendale, $\mathrm{Pa}, \mathrm{USA}, 2000$.

[33] A. E. Ares, S. F. Gueijman, and C. E. Schvezov, "Latent heat evolution during solidification of aluminum based alloys," in Light Metals 2001, pp. 1077-1084, TMS, Warrendale, Pa, USA, 2001. 

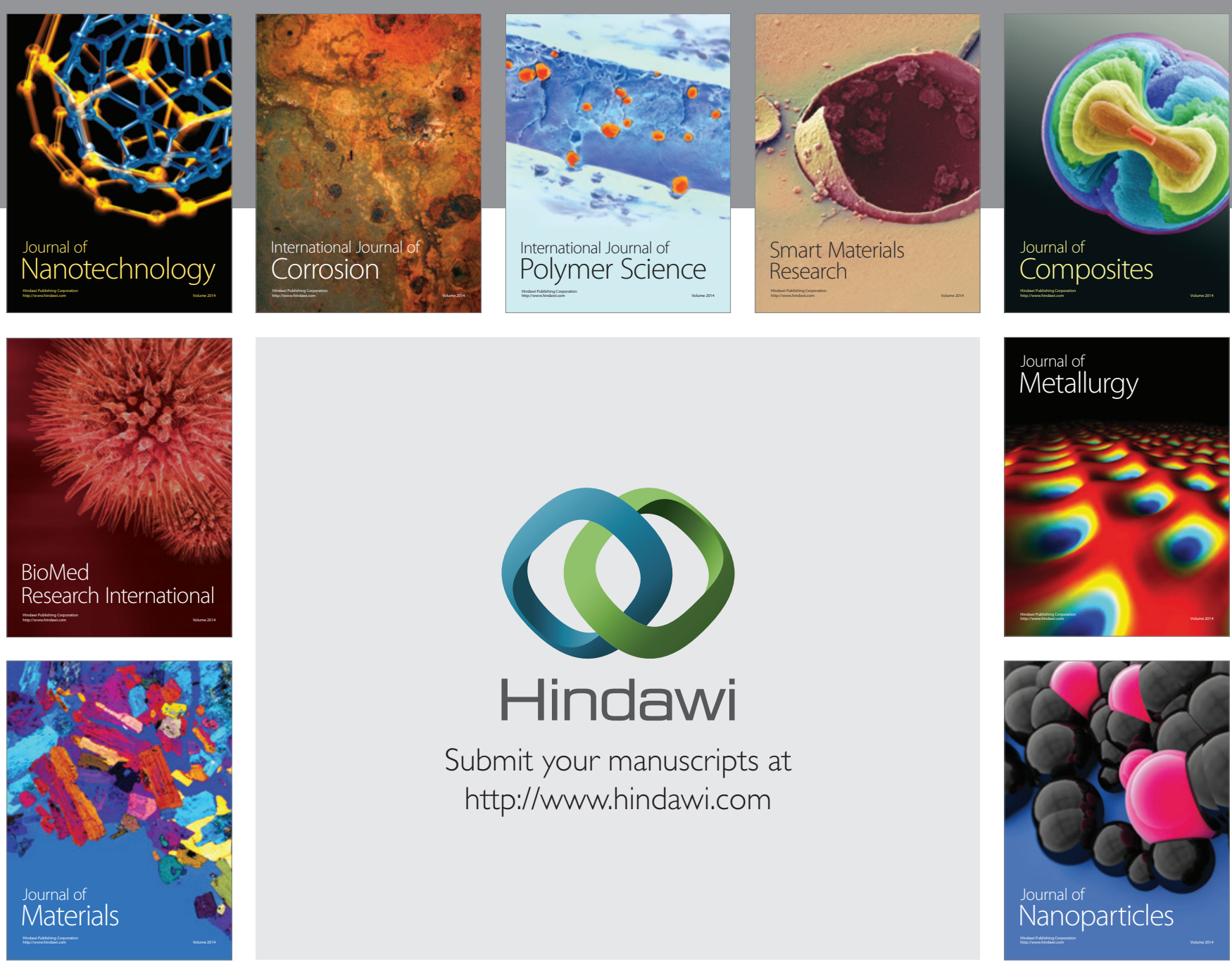

Submit your manuscripts at http://www.hindawi.com
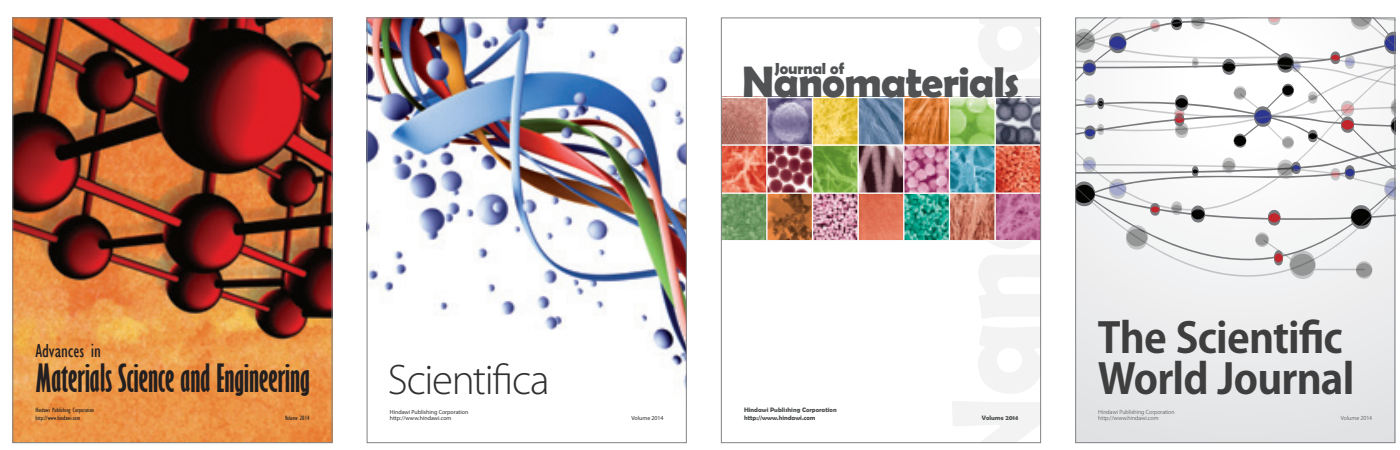

\section{The Scientific World Journal}
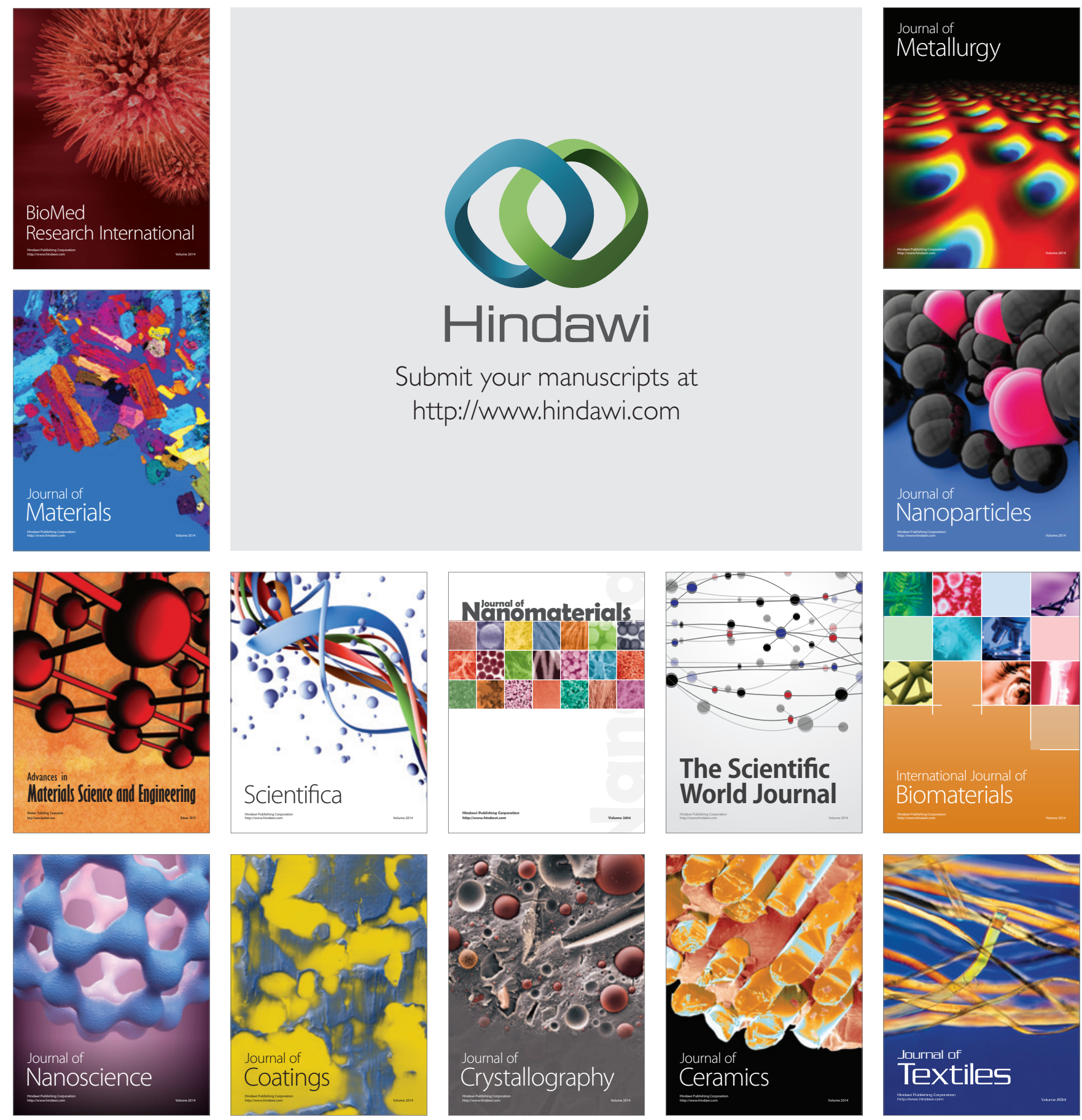